\title{
Kecerdasan Kultural Siswa Muslim dan Non-Muslim Di Kota \\ Curup: Sebuah Eksplorasi Kualitatif
}

\author{
Hendra Harmi \\ Institut Agama Islam Negeri (IAIN) Curup \\ hendra3_harmi@yahoo.co.id \\ Nur Jannah \\ Institut Agama Islam Negeri (IAIN) Curup \\ nurjannahtaklim@gmail.com \\ Muhammad Sholihin* \\ Institut Agama Islam Negeri (IAIN) Curup \\ sholihin@iaincurup.ac.id
}

\begin{abstract}
Cultural intelligence for high school students becomes important along with the many attitudes and behaviors of a person who are destructive and growing among students such as being against differences both in terms of culture, religion, language and ethnicity. Even though Indonesia as a nation and country has a uniqueness, diversity from various aspects. Therefore, for the younger generation, especially high school students, intelligence in social interaction is needed in the midst of high levels of difference, this is done as a way to minimize discrimination or anti-diversity attitudes. High cultural intelligence possessed by students in schools is expected to be able to improve harmony amid cultural differences. This article intends to explore the cultural intelligence of high school students in Rejang Lebong Regency from the perspective of Muslim and non-Muslim students.
\end{abstract}

Keywords: Cultural Intelligent, Multiculturalism, Discrimination, Tolerances and Inclusivism

Abstrak: Kecerdasan kultural bagi siswa Menengah Atas menjadi penting seiring dengan banyaknya sikap dan perilaku yang desktruktif dan tumbuh di kalangan pelajar seperti anti terhadap perbedaan--baik dari sisi budaya, agama, bahasa dan etnisitas. Padahal Indonesia sebagai suatu bangsa dan

Belajea: Jurnal Pendidikan Islam Vol. 5, No 01, 2020: 93-112 p-ISSN 2548-3390; e-ISSN 2548-3404, DOI:10.29240/belajea.v5 available online at:http://journal.staincurup.ac.id/indek.php/belajea 
94 | Belajea: Jurnal Pendidikan Islam, Vol. 5, No. 01, 2020

negara memiliki keunikan, keberagaman dari berbagai aspek. Karena itu, bagi generasi muda khususnya siswa SMA dibutuhkan kecerdasan dalam berinteraksi sosial ditengah tingginya tingkat perbedaan, hal ini dilakukan sebagai salah satu cara untuk meminimalisir sikap diskriminasi atau anti terhadap perbedaan. Kecerdasan kultural tinggi yang dimiliki oleh siswa di sekolah diharapkan mampu meningkatkan harmoni di tengah perbedaan budaya. Artikel ini bermaksud ingin mengesplorasi tentang pecerdasan budaya yang dimiliki oleh siswa SMA di Kabupaten Rejang Lebong dari sudut pandang siswa Muslim dan non Muslim.

Kata Kunci: Cultural Intelligent, Multikulturalisme, Diskriminasi, Toleransi dan Inklusifism.

\section{Pendahuluan}

Multikulturalisme tidak hanya sebagai sebuah terma yang merujuk pada perilaku dan respon individual atau masyarakat terhadap diversitas dan menerimanya sebagai sesuatu keniscayaan. Tapi sesungguhnya multikulturalisme berisi seperangkat kepercayaan dan pandangan yang mendalam terhadap perbedaan dan menerimanya sebagai sebuah sesuatu yang alamiah dan bersipat naturalistik. Dengan asumsi bahwa manusia tidak dapat hidup dalam entitas tunggal atau menutup mata dari perbedaan.

Sementara itu, Parekh (2006) mengidentifikasi bahwa masyarakat multikultural dapat merasa sebagai sebuah masyarakat yang monokulturalistik atau masyarakat multikultural, sangat tergantung pada respon normatif terhadap diversitas kultural. Dalam makna lain, bahwa pendekatan terhadap masyarakat multikultural dapat dikategorikan ke dalam dua bentuk utama, yakni monokulturalis dan multikulturalis. ${ }^{1}$ Ini artinya, dalam masyarakat multikultural, sikap, perilaku dan respon terhadap perbedaan budaya, etnis, bangsa dan agama sangat determinan dengan sistem norma yang diberlaku pada masyarakat tersebut. Dalam konteks inilah, multikulturalisme sebagai sebuah pengalaman pada sekolah atau institusi pendidikan di mana peserta didiknya beragam dalam aspek agama dan etnis layak dimaknai.

${ }^{1}$ Bikhu Parekh, Rethinking Multiculturalism: Cultural Diversity and 126 NO. 1. VOL. I. 2008 Political Theory (Cambridge: Harvard University Press, 2002)., 36. 
Fenomena bicultur atau hidup dalam realitas di mana ada dua budaya atau bahkan lebih atau multiple-culture tidak hanya ditemukan pada masyarakat secara luas. Tapi pada institusi sosial seperti sekolah, juga ditemukan dua hal tersebut. Agaknya, keadaan ini tidak dapat terelakan atau dihindari. Karena institusi pendidikan adalah corpus yang terbuka bagi siapapun, tanpa membedakan identitas, ras, etnisitas dan agama. Sehingga, sekolah dapat diistilahkan multicultural sphere atau ruang multikultural. Karena itu, idealnya nilai-nilai multikultural tumbuh padanya, dan multiculturalism awareness berkembang subur atau bahkan layak dijadikan pilot-project bagaimana model multikulturalisme dikembangkan dan kemudian diterapkan pada masyarakat yang lebih luas.

Hal ini dapat dimaklumi, karena tujuan dari pendidikan multikultural adalah mempersiapkan siswa agar mampu bertahan hidup dan berinteraksi dalam dunia dengan diversitas yang tinggi. Tidak hanya itu, pendidikan multikultural juga bertujuan meningkatkan kapasitas komunikasi siswa dalam berkomunikasi dengan orang lain melalui partisipasi secara aktif dalam proses belajar dan dengan mengunakan segala pengalaman mereka dalam sebuah kelas yang kondusif. Untuk mendorong ini, maka dibutuhkan pengajaran yang efektif dalam sebuah kelas multikultural dengan menerapkan strategi yang berorientasi pada sensitifitas-kultural dan menciptakan kesempatan yang equal untuk pencapaian kesuksesan akademik dan pengembangan personal bagi seluruh peserta didik. ${ }^{2}$ Hal Ini akhirnya akan berdampak bagaimana bagaimana kecerdasan kultural mereka dalam menyikapi perbedaan. Agnes Balogh (2011) secara sederhana, merumuskan makna kecerdasan budaya yaitu kemampuan individu dalam menghadapi tantangan kultural dengan sukses. Berkenaan dengan itu, maka penulis ingin meneliti dan menemukan bagaimana kemampuan seseorang siswa SMAN 01, SMAN 02, dan SMA Xaverius di Kabupaten Rejang Lebong mampu beradaptasi secara cerdas ketika berinteraksi dengan siswa yang berbeda agama. Untuk melakukan eksplorasi bagaimana kecerdasan kultural siswa muslim dan non muslim pada Sekolah Menengah Atas di Kota Curup, maka riset ini menggunakan pendekatan kualitatif, dengan desain grounded theory, dimana informan menjadi sumber primer dalam merumuskan konsep dan model kecerdasan kultural yang melekat secara personal di kalangan siswa muslim dan non-muslim di Kota Curup. Dalam penerapannya, instrumen pengumpulan data

${ }^{2}$ Hassan Aydin, "Graduate Students Perceptions' on Multicultural Education: A Qualitative Case Study", Eurasian Journal of Educational Research, no. 57 (2014): 30. 
96 | Belajea: Jurnal Pendidikan Islam, Vol. 5, No. 01, 2020

dalam kajian ini menggunakan strategi Focus Group Discussion, dengan mengeksplorasi pengalaman, persepsi dan opini siswa muslim dan non muslim terhadap multikulturalisme. Sehingga, dapat dipotret bagaimana kecerdasan kultural mereka ketika berhadapan pada problematika multikulturalisme dalam keseharian mereka.

\section{Pembahasan}

Kecerdasan Kutlural

David C. Thomas, Zeynep Aycan, dan Yuan Liao, dengan mendalam dan terukur merumuskan makna; skala pengukuran kecerdasan kultural. Dalam kajiannya, David C. Thomas menjelaskan cultural intelligence dalam konteks interaksi antar-budaya. Dalam konteks ini pula, David C. Thomas berusaha mengkonseptualisasikan cultural intelligence yang merujuk pada sebuah sistem kemampuan berinteraksi, yang mengambarkan bagaimana elemen ini saling berinteraksi secara kultural, yang kemudian melahirkan kecerdasan dalam berprilaku. $^{3}$

Dalam konteks ini, kecerdasan atau intelligence perlu dipahami terlebih dahulu, apa maknanya. Secara teori, kecerdasan didefinisikan secara kontekstual_-determinan dengan field dimana ia didefinisikan. Dalam konteks ini, ada beberapa field yang memaknai kecerdasan atau intelligence tersebut: Pertama, ia merujuk ada kajian tentang ide-ide dalam psikologi-kognitif. Misalnya, term 'global mindset' yang secara luas digunakan dalam literatur management. Kedua, memisahkan perbedaan konstruk individual dari institusi dan pengaruh lingkungan terhadap perilaku antar-budaya. ${ }^{4}$ Akan tetapi, mengkategorikan itu memerlukan pemahaman yang baik terhadap makna intelligence atau kecerdasan, dimana "intelligence", merupakan konstruk sainstik fundamental yang tidak dapat diverikasikan secara fisik. ${ }^{5}$

Sementara itu, Sternberg mengemukakan difinisi bahwa mengidentifikasi kecerdasan sebagai kemampuan beradaptasi-melakukan seleksi dan

${ }^{3}$ David C. Thomas Günter Stahl and Efrat Elron, "Cultural Intelligence: Domain and Assessment," International Journal of Cross Cultural Management Vol. 8, no. 2 (2008): hlm. 123-124.

${ }^{4}$ Zeynep Aycan David C. Thomas, "Cultural Intelligence: A Theory-Based, Short Form Measure," Journal of International Business Studies, no. January (n.d.): hlm. 124.

${ }^{5}$ David C. Thomas, hlm. 124. 
berkontribusi terhadap lingkungan. Tampaknya, definisi ini senada dengan definisi yang dikemukan oleh Binet dan Simon. Keduanya sama-sama mendefinisikan 'kecerdasan' sebagai kemampuan beradaptasi dengan lingkungan dimana individu hidup. Earley mendefinisikan kecerdasan budaya sebagai: "kemampuan seseorang untuk beradaptasi secara efektif terhadap konteks kultural baru." Dengan elemen konstituen terdiri dari: cognitive; dan motivational behavioral. Sementara itu, Thomas \& Inkson (2003) mendefinisikan 'cultural intelligence' sebagai: "sesuatung yang melibatkan pemahaman terhadap interaksi inter-kultural secara fundamental, dalam membangun pendekatan mindful terhadap interaksi-kultural, dan pada akhirnya berguna dalam mengembangkan kemampuan adaptasi dan menyajikan perilaku yang baik dan efektif dalam kondisi atau lingkungan dimana perbedaan interkultural (diversity) sangat tinggi adanya. Dengan demikian dapat disimpulkan bahwa kecerdasan merupakan kemampuan seseorang dalam berinteraksi dan beradaptasi dengan situasi lingkungan sosial yang berbeda dari berbagai aspek, serta mampu secara dinamis berjuang dan berhasil dalam menata karis kehidupannya.

David C. Thomas menyakini bahwa produk dari kecerdasan kultural adalah interaksi interkultural yang efektif. Tesis yang dikemukakan David C. Thomas ini, tentunya mendorong lahirnya pertanyaan: "apakah indikator yang mendorong tindakan kecerdasan kultural?" sebelum membahas indikator dari kecerdasan kultural tersebut, agaknya penting memaparkan karakteristik dari interaksi interkultural yang efektif, yakni: Pertama, "Good personal adjusment", yang diindikasikan melalui perasaan puas dan bahagia. Seorang individu yang memiliki well-adjusted akan berpendapat bahwa mereka merasa comfortable tatkala berinteraksi dengan budaya; orang yang berbeda dengan diri mereka atau bilamana mereka berinteraksi dalam lingkungan yang secara kultural berbeda,mereka tidak akan mengalami 'goncangan' atau shock culture ketika mengalami interaksi yang disebutkan di atas. Kedua, Pengembangan dan pemiliharaan hubungan interpersonal yang baik dengan entitas yang secara kultural berbeda. Ini secara khusus, penting untuk menilai aspek-aspek efektivitas dari perspektif yang secara kultural berbeda dari yang lain. Karena hubungan ini bersifat mendidik secara natural dan akan diterima sebagai sesuatu yang positif, kendati dalam level berbeda antara satu individu dengan individu lainnya. Kedua, Efektivitas dari the completion of task-related goals. Ketika tujuan berbeda antar satu

${ }^{6}$ David C. Thomas, hlm. 125. 
98 | Belajea: Jurnal Pendidikan Islam, Vol. 5, No. 01, 2020

individu degan individu lain, dari satu situasi ke situasi lain, kecakapan akan selalu menjadi produk dari interaksi yang efektif dalam settingcross-culture. ${ }^{7}$ Efektifitas dari interaksi interkultural ini sejatinya dapat juga diartikan, secara otomatis, sebagai indikator dari kecerdasan kultural. Sederhananya, individu yang memiliki kecerdasan kultural akan mampu melakukan interaksi interkultural yang baik dan efektif. Mereka bukanlah individu yang merasa asing, aneh, ataupun shock tatkala berhadapan dengan diversitas dimana mereka hidup dan berinteraksi dengan orang lain. Jianguanglung Dangmei (2016), menyusun indikator kecerdasan kultural, sebagai berikut: Pertama, Metakognitif. Ini merepresentasikan proses mental yang digunakan individu untuk mendapatkan pemahaman terhdap pengetahuan kultural atau the cultural knowledge seperti kesadaran, pengontrolan dan pemikiran individual yang berhubungan dengan kultur. ${ }^{8}$ Secara praktis, seseorang dengan metakognitif kecerdasan kultural yang tinggi cenderung memiliki kesadaran terhadap preferensi kultur orang lain, dan penilaian mental mereka tumbuh tatkala mereka berinteraksi. ${ }^{9}$ Kedua, Kognitif. Ini merefleksikan pengetahuan normatif; praktis dan peran dalam perbedaan kultural yang dihasilkan dari pendidikan, dan pengalaman personal. ${ }^{10}$ Ia meliputi pengetahuan ekonomi, legal-system, sosiolinguistik, dan interpersonal arragement of different cultures dan subcultures dan koteks dasar dari nilai-nilai kultural. Secara teoritis, seseorang dengan kognisi kecerdasan kultural yang tinggi akan mampu mengakui kesamaan dan diversitas kultural yang berbeda.

Ketiga, "Motivational". Ini memanifestasikan kemampuan untuk memberikan antensi secara langsung dan energi untuk mempelajari dan menghadapi tantantangan dalam situasi yang ditentukan sepenuhnya oleh perbedaan kultural. Ini menyediakan kontrol terhadap afeksi; kognisi dan perilaku yang membantu dalam mencapai tujuan. Ini menghantarkan seseorang untuk menyesuaikan diri dengan interest dan curiousity untuk menilai lingkungan yang tidak familiar, tatkala merespon ambiguitas. Keempat, "Behavioral", yakni kemampuan untuk memanifestasikan perilaku verbal dan non verbal yang sesuai dengan perbedaan kultural orang lain selama melakukan interaksi. Secara empiris, individu yang memiliki perilaku kecerdasan kultural yang tinggi akan mampu menampilkan kata-kata, tone, gesture, facial manifestation yang sesuai dengan

\footnotetext{
${ }^{7}$ David C. Thomas, hlm. 125-127.

${ }^{8} \mathrm{hlm} .285$.

${ }^{9} \mathrm{hlm} .286$.

${ }^{10}$ hlm. 285.
} 
lingkungan dimana interaksi dilakukan. ${ }^{11}$ Keempat komponen penting ini sekaligus menjadi indikator dari seberapa cerdas seseorang secara kultural. Dengan asumsi, semangkin tinggi kecerdasan kultural seseorang, maka semangkin cerdas dan efektif interaksi inter-kultural yang dilakukan pada lingkungan dengan diversitas yang tinggi.

\section{Hasil Penelitian}

\section{Kecerdasan Kultural Siswa Muslim dan Non-Muslim di Curup}

Untuk memahami bagaimana kecerdasan kultural siswa muslim dan non-muslim pada Sekolah Menengah Atas di Kota Curup. Maka diperlukan stimulus atau pernyataan yang bersipat kognitif kepada para informan melalui Focus Group Discussion. Dalam prakteknya, focus group discussion dibagi berdasarkan beberapa tema untuk melihat seberapa cerdas siswa muslim dan non muslim dalam merespon berbagai kasus yang terkait dengan perbedaan budaya dan agama.

Pertama, terkait definisi multikultural. Secara teori multikultural diartikan sebagai: "sesuatu yang merujuk pada eksistensi pluralitas etnis, kultur dalam satu masyarakat." 12 Ini menegaskan bahwa multikulturalisme merupakan kondisi dimana dalam suatu masyarakat terdapat diversitas agama; budaya; dan etnisitas. Untuk dapat berinteraksi dengan baik dalam masyarakat plural seperti ini, maka diperlukan kecerdasan dan inklusifitas dalam memahami perbedaan tersebut. Dalam konteks ini pula, Carl A. Grant (2005) memaknai multikultural sebagai satu kondisi dimana entitas sosial hidup dengan beragam identitas, baik dari segi agama; budaya; etnis dan latarbelakang geografi lainnya. ${ }^{13}$ Secara empiris, apa yang diajukan sebagai definisi dan pemaknaan oleh informan tidak terlalu berbeda secara teoritis sebagaimana halnya yang ditawarkan oleh sarjana sosial terkait 'makna multikulturalisme'. Dalam hal ini, seorang informan dari SMAN 01, mengemukan bahwa multikulturalisme merupakan satu keadaan dimana orang berbeda agama; ras; dan suku. Meskipun berbeda, tetap diartikan satu,

\footnotetext{
${ }^{11}$ Jianguanglung Dangmei, "Cultural Intelligence: Bridging the Cultural Differences in the Emerging Markets," Indian Journal of Research Vol. 5, No. 9 (2016). 285.

${ }^{12}$ John Horton, Liberalism, Multiculturalism and Tolerantion (New York: Palgrave McMillan, 1993), hlm. 2.

${ }^{13}$ Carl A.Grant (ed.), Reasearch and Multicultural Education: From the Margins to the Mainstream (London: The Falmer Press, 2005), hlm. 10.
} 
100 | Belajea: Jurnal Pendidikan Islam, Vol. 5, No. 01, 2020

atau bbineka tunggal ika. ${ }^{14}$ Ketika diberikan stimulus dengan cara mengajukan ilustrasi berupa kartun, ia dengan fasih menjelaskan bahwa perbedaan etnis, agama, dan ras seperti melayu, negroit, china dan lain sebagai realitas bangsa. Pemaknaan semacam ini menjadi indikator bahwa informan mengerti dan paham bahwa multikulturalisme adalah kondisi yang tidak dapat dihindari oleh manusia. Hal yang sama, tapi lebih subtantif informan lain menyampaikan bahwa: "..dalam perbedaan upaya untuk beradaptasi dengan budaya yang lain mestilah diutamakan. Karena sejak kecil, kita sudah diajarkan nilai-nilai perbedaan." 15

Sementara itu, informan dari SMAN 02 menawarkan makna multikulturalisme sebagai: "berbeda mensyaratkan adanya satu tujuan, yang dapat dicapai secara bersama dalam satu kelompok masyarakat." ${ }^{\text {16 }}$ Pemaknaan ini mensyaratkan adanya tujuan kolektif, yang menjadi fondasi bagi warga negara yang berbeda identitas sosial; budaya untuk hidup dan saling berinteraksi antara dengan lainnya. Hal yang sama juga diutarakan oleh informan dari SMA Xaverius, dimana menurutnya: "perbedaan etnis; agama dan budaya mendorong individu untuk dapat terbuka satu dengan lainnya, dan mampu memahami perbedaan dengan baik." 17 Informasi yang disampaikan oleh informan ini menegaskan pemahaman inklusif siswa Sekolah Menengah Atas di Kota Curup. Secara teoritis, merujuk pada tesis yang diajukan oleh Sangmi Cho \& Michelle E. Mor Barak (2008) bahwa karakteristik diversity berhubungan erat dengan inklusifitas individu dimanapun mereka ada dan melakukan interaksi. Sebab dalam konteks teori identitas sosial, individu cenderung melakukan kategorisasi terhadap diri mereka berdasarkan demografi-umur, gender, ras, dan afiliasi sosial. Ini dilakukan dalam rangka memvalidasi identitas sosial mereka untuk kemudian ditampilkan ke anggota sosial yang mereka identifikasi sama dengan diri mereka. ${ }^{18}$ Namun ketika individu dapat melampaui kecenderungan ini, maka ia dapat dikata inklusif dan memiliki kecerdasan kultural. Tentu hal itu bukan

${ }^{14}$ Focus Group Discussion, Wildan, Siswa SMAN 01. 21/12/2018

${ }^{15}$ Focus Group Discussion, Nita Hairina, Siswa SMAN 01. 21/12/2018

${ }^{16}$ Focus Group Discussion, Bonas Hasugian, Siswa SMAN 02. 23/12/2018

${ }^{17}$ Focus Group Discussion, Anastasya, Siswa SMA Xaverius, 08/12/2018

${ }^{18}$ Sangmi Cho Michaile E. Mor Barak, "Understanding of Diversity and Inclusion in a Perceived Homogeneous Culture: A Study of Organizational Commitment and Job Performance Among Korean Employees" (Administration in Social Work, 2008), hlm. 105106. 
taken for granted bagi individu. Tetapi proses itu tumbuh seiring meningkatnya pengalaman multikultural seseorang. Dalam hal ini, bagaimana sesungguhnya implikasi pengalaman multikultural Siswa Muslim dan Non Muslim di Sekolah Menegah Atas di Kota Curup terhadap Kecerdasan Kultural mereka?

Merujuk pada pandangan Agnes Balogh, untuk memahami implikasi pengalaman multikultural terhadap kecerdasan kultural, maka penting menguji pemahaman individu terhadap berbagai persoalan multikulturalisme serta memahami bagaimana pemaknaan mereka terhadap perbedaan ketika mereka menjadi bagian penting dari perbedaan tersebut. Pemahaman tersebut kemudian dikelompokkan ke dalam 4 (empat) indikator, yakni: metacognitive; cognitive; motivational dan behavioural. ${ }^{19}$ Pertama, "metacognitive" sebagai hal yang dipahami dengan proses bagaimana individu memperoleh pengetahuan tentang kognitif, atau knowing about knowing. Hal ini diteorikan oleh Bloom, yang kemudian dikenalkan dengan istilah Bloom's Taxonomy. Ini dapat diilustrasikan sebagai berikut:

\section{Diagram 1. Bloom's Taxonomy}

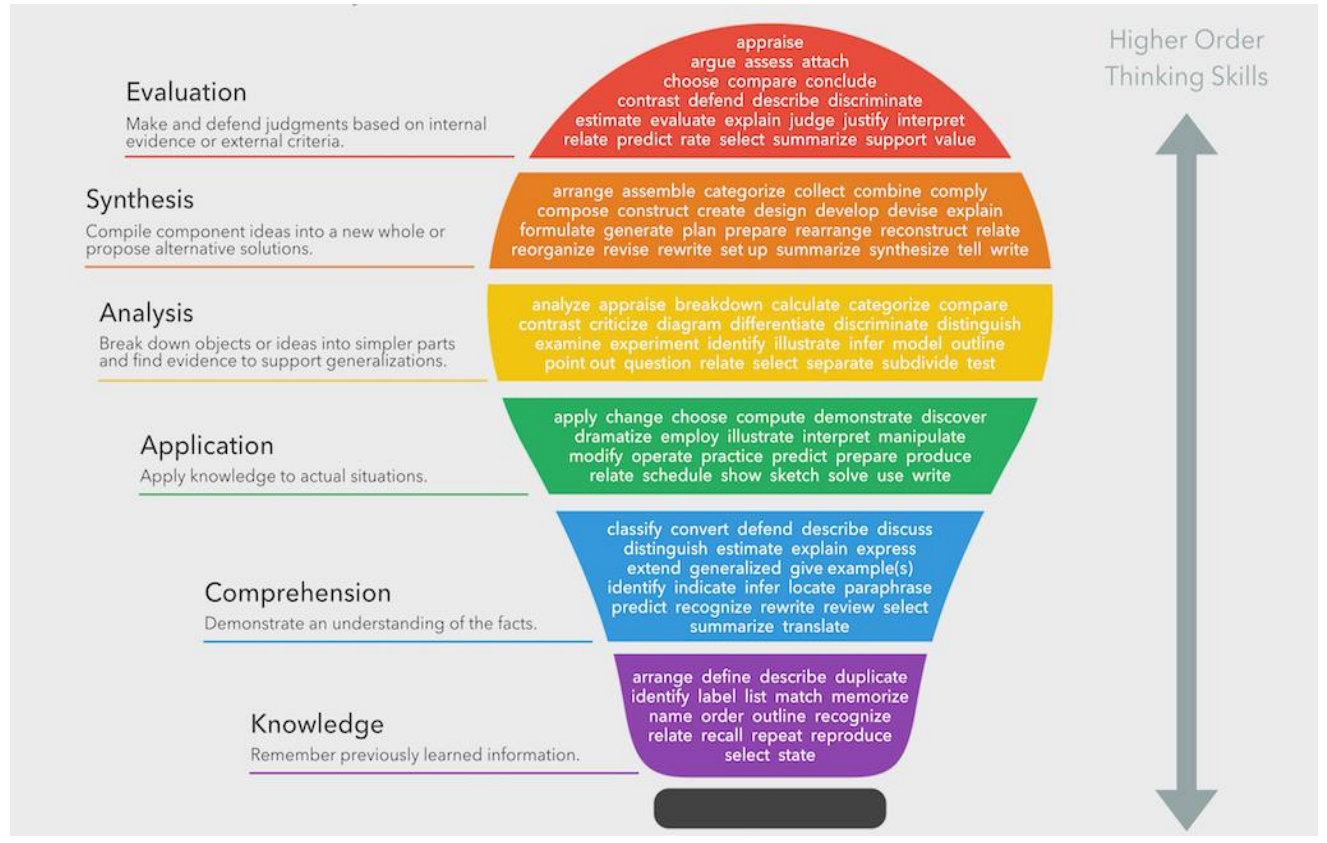

4.

${ }^{19 ،}$ “Cultural Intelligence: The Key Competence of the Twenty-First Century," hlm. 
102 | Belajea: Jurnal Pendidikan Islam, Vol. 5, No. 01, 2020

Secara komprehensif, metakognisi dimaknai sebagai kemampuan individu dalam mengevaluasi; membangun sintesis; melakukan analisis; menerapkan pengetahuan dalam situasi aktual; mendemonstrasikan pemahaman terhadap fakta serta mengingat berbagai informasi yang didapatkan terhadap permasalahan. Dalam konteks ini, siswa muslim dan non muslim pada Sekolah Menengah Atas di Kota Curup distimulus dalam focus group discussion, dengan memberikan kasus dan persoalan terkait multikulturalisme. Ketika mereka berhadapan dengan problematika multikultural ini, maka secara kualitatif, dapat dipahami bagaimana proses metakognisi mereka dalam mengindentifikasi persoalan yang ada. Dimensi yang diamati dan dipahami secara kualitatif meliputi bagaimana mereka menganalisis persoalan; dan melakukan demonstrasi terhadap persoalan tersebut. Ketika peserta focus group discussion, untuk kemudian disebut dengan informan, dari SMAN 01 dihadapkan dengan fakta berhubungan dengan permasalahan; diskursus terkait multikulturalisme. Mereka dengan cerdas mampu melakukan analisis yang baik. Misalnya, ketika distimulus dengan sebuah informasi dari media massa ketika Paus Fransiskus mengucapkan selamat hari raya Idul Fitri, informan memaknai bahwa:

“...Paus mengucapkan idul fitri itu untuk menghormati dan menghargai orang yang berbeda agama dengan dia dan untuk menunjukkan adanya toleransi antar ummat beragama."20

Terkait hal yang sama, informan dari SMAN 02 mengutarakan:

"Paus merupakan pemimpin tertinggi katolik dia tidak memandang perbedaan apapun yang ada didunia ini. Beliau tetap mengucapkan selamat ketika ada Imlek, Idul Fitri. Bahkan secara konsisten dirinya mengucapkan selamat kepada ummat-ummat yang berbeda."21

Informan lain dari SMA Xaverius mengemukakan pemaknaanya:

Saya pernah membaca buku tentang paus fransiscus ini tentang 90 cara hidup ala pope prancis. walaupun beliau ini sangat dikagumi oleh semua orang tetapi beliau ini tidak mau disanjung-sanjung...jadi beliau ini

${ }^{20}$ Focus Group Discussion. Stanley Marco Effendi. Siswa SMAN 01. Tanggal 21/12-2018.

${ }^{21}$ Focus Group Discussion. Hoksius Deariman Saragih. Siswa SMAN 02. Tanggal 21/12-2018. 
sangat sederhana. Dalam buku tersebut saya juga belajar bagaimana hidup sederhana dan bagaimana kita menghargai orang yang berbeda dan orang ini sangat toleran."22

Bagaimana ketiga informasi ini diinterpretasikan? Ketiga informasi yang diutarakan oleh informan tersebut, agaknya dapat dikelompokkan sebagai argumentasi atas proses metakognisi yang secara alamiah, dan spontan dialami oleh para siswa muslim maupun non muslim pada Sekolah Menengah Atas di Kota Curup. Dinilai spontan, karena memang secara empiris setiap saat mereka dihadapkan pada perbedaan dan berinteraksi dengan orang yang berbeda secara kultural; dan agama antara satu dan lainnya. Ini tentu menjadi pra-kondisi mengapa kemudian mereka 'terbiasa' dan mampu beradaptasi secara inklusif terhadap individu yang berbeda dengan diri mereka sendiri. Kecerdasan seperti itu, tidak taken for granted atau tumbuh begitu saja tanpa proses. Karena sesungguhnya, kecerdasan dalam menyikapi perbedaan akan seiring dan linier dengan proses metakognitif secara konsisten dilakukan individu. Ini yang tampak pada siswa muslim dan non muslim pada Sekolah Menengah Atas di Kota Curup. Hal ini sejalan dengan teori yang dikemukakan oleh Wiston R. Sieck; Jennifer L. Smith \& Louise J. Rasmussen (2013), dimana menurut mereka: "strategi metakognitif secara umum diterapkan untuk menumbuhkan apa yang diistilahkan dengan sense of cultural anomalies, ${ }^{23}$ kemampuan ini sangat penting adanya dalam masyarakat multikultural. Sehingga perbedaan menjadi sesuatu yang dinilai niscaya dan wajar. Karena metakognitif sendiri merupakan proses dimana individu berusaha memahami pengetahuan kultural. ${ }^{24}$ Artinya, setiap individu akan berusaha memahami orang lain secara kultural sebelum mereka melakukan interaksi. Pada tahap ini, mereka berusaha memahami dimensi perbedaan yang melekat pada entitas lain, tanpa terlibat dan terjatuh pada sikap penolakan atau mempersalahkan perbedaan tersebut. Lantas, tahap berikutnya apa?

${ }^{22}$ Focus Group Discussion. Anastasya. Siswa SMA Xaverius. Tanggal 08/12-2018

${ }^{23}$ Winston R. Sieck, Jennifer L. Smith and Louise J. Rasmussen, "Metacognitive Strategies for Making Sense of Cross-Cultural Encounters," Journal of Cross-Cultural Psychology Vol. 44, no. 6 (2013): hlm. 1007.

${ }^{24}$ Jennifer L. Smith and Louise J. Rasmussen, hlm. 109. 
104 | Belajea: Jurnal Pendidikan Islam, Vol. 5, No. 01, 2020

Kedua, "cognitive" — sebagai sebuah proses dimana individu berusaha mendapatkan dan memahami informasi terkait berbagai hal. ${ }^{25}$ Dalam kajian ini, tentu terkait perbedaan identitas, bukan untuk mempersoalkan perbedaan tersebut. Tapi untuk memahami esensinya, agar menjadi kapital untuk beradaptasi dalam perbedaan tersebut. Hanya saja dalam strategi dan bagaimana mendapatkan informasi, ada berbagai style dan cara yang khas serta spesifik dilakukan oleh individu. Paige Lucas-Stannard telah mengurai hal tersebut. Menurutnya, setidaknya ada beberapa cara atau style dari proses kognitif, yakni: reflection-impulsivity; field dependent-independence, holist-serialist dan deep-level/surface-level processing. ${ }^{26} \mathrm{Hal}$ yang paling umum dari berbagai style tersebut adalah reflectionimpulsivity, atau proses pengumpulan informasi dengan melihat detail dan berefleksi terhadap sumber informasi dan informasi itu sendiri. Pola ini yang kemudian juga ditemukan secara empiris pada siswa muslim dan non muslim pada Sekolah Menengah Atas di Kota Curup. Menguatkan tesis ini, ada beberapa evidence atau fakta yang dikemukan, dan sepenuhnya bersumber dari informan kajian ini.

Seorang informan dari SMAN 01, distimulus dengan informasi yang menunjukkan adanya aksi terorisme yang dilakukan oleh oknum beragama Islam. Lantas, ditanyakan: "apakah saudara menyakini bahwa umat Islam itu teroris?" Dengan spontan, ia mengemukakan bahwa:

“..Kalau menurut pendapat saya sendiri saya tidak percaya bahwa ummat Islam yang melakukan dan saya juga pernah mendengar bahwa Islam tidak pernah mengajarkan menyebarkan kebencian; membuat kerusuhan. Jadi saya tidak terhasut."27

Dalam kasus yang berbeda, informan lain bahkan mengajurkan untuk berusaha memahami agama lain, agar tidak salah dalam melakukan interaksi sosial. Ia mengutarakan bahwa: "..Agama kita begini mereka tidak seperti Budha tidak boleh makan daging. Jangan samapai jika kita ngajak makan daging yang mereka tidak bisa memakannya [haram]. 'Kan tidak enak. Jadi belajar agama lain

${ }^{25}$ "What Is Cognition? A Functional-Cognitive Perspective," hlm. 2.

${ }^{26}$ Paige Lucas-Stannard, "Cognitive Styles: A Review of the Major Theories and Their Application to Information Seeking in Virtual Environments," Bibliographic Essay, March 13, 2019, hlm. 3, www.personal.kent.edu/ plucasst/Cognitive\%20Styles.pdf.

${ }^{27}$ Focus Group Discussion. Richard. Siswa SMAN 01. Tanggal 21/12-2018. 
itu untuk memahami satu sama lain."28 Ini menegaskan bahwa mencari informasi terhadap perbedaan, atau tradisi yang berbeda dalam agama lain, sangat penting gunanya untuk melangsungkan interaksi sosial, agar terbangun sikap mutual-understanding antara umat yang berbeda agama; budaya dan etnis. Ini yang diperlihatkan oleh siswa SMAN 01 Kota Curup. Hal yang senada juga diutarakan oleh informan dari SMAN 02, yakni:

“..Berupaya untuk memahami agama sendiri. Bahkan mengingatkan teman kita yang beda agama untuk memahami agama mereka. Agar mengerti bagaimana hukum dalam agama kita, dan agama orang lain." ${ }^{29}$

Informan lain juga mengutarakan:

"Saya pernah belajar dari you tube tentang agama ibu, saya yang Islam, bahwa orang muslim mengucapkan selamat natal pada agama Kristen tidak boleh mengucapkan selamat kepada agama Kristen. mungkin karena itu mereka tidak mau mengucapkan selamat natal. Namun ini saya hargai, karena begitulah cara mereka menjaga kepercayaan mereka. Jadi tidak perlu ada paksaan dalam mengucapkan selamat natal." 30

Sementara itu, informan dari SMA Xaverius mengemukakan:

"Mari kita belajar mengenal apa yang ada di Indonesia dan belajar menerima segala perbedaan karena Indonesia ini sangat unik. Keunikan yang tidak dimiliki oleh negara-negara lain. Indonesia punya banyak perbedaan yang bisa diterima oleh masyarakatnya dari mulai Bahasa, suku, dan banyak sekali perbedaan lainnya." ${ }^{31}$

Kata kunci dari informasi yang dikemukan oleh informan dari tiga Sekolah Menengah Atas di Kota Curup adalah keinginan yang kuat untuk mengenal dan mendapatkan informasi tentang berbagai perbedaan dalam agama; budaya dan etnis lainnya. Kognisi semacam ini tidak saja mendorong mereka mampu dalam berinteraksi, tapi juga sukses dalam beradaptasi dalam lingkungan

\footnotetext{
${ }^{28}$ Focus Group Discussion. Desi. Siswa SMAN 01. Tanggal 21/12-2018.

${ }^{29}$ Focus Group Discussion. Santo Yosep Sihombing. Siswa SMAN 02. Tanggal 21/12/2018.

${ }^{30}$ Focus Group Discussion. Noconael Steven. Siswa SMAN 02. Tanggal 21/12/2018. $08 / 12 / 2018$

${ }^{31}$ Focus Group Discussion.Natasya Intan. Siswa SMA Xaverius. Tanggal
} 
dengan level diversitas yang relatif tinggi. Merujuk pada Ben R. Newel \& Arndt Broder (2008) bahwa proses kognitif merupakan upaya yang dilakukan individu untuk memahami entitas, situasi yang dihadapinya. Sehingga informasi tersebut berguna dalam mengambil keputusan, dan merumuskan pola perilaku. ${ }^{32}$ Tesis yang diajukan oleh Ben R. Newel \& Arndt Broder mengukuhkan fakta empiris yang ditemukan, dan telah diuraikan sebelumnya. Hanya saja dalam bentuk yang lebih spesifik, usaha untuk memahami perbedaan bagi siswa muslim dan non muslim pada Sekolah Menengah Atas di Kota Curup, ditujukan untuk mengenal perbedaan entitas lain, dan dengannya dapat memposisikan diri secara tepat. Dalam kondisi ini adaptasi, dan interaksi sosial yang baik akan terbangun, sehingga mereka tidak lagi mempersoalkan perbedaan tersebut.

Ketiga, "Motivational-Cultural Intelligence"-sebagai kekuatan yang muncul dari diri individu untuk berinteraksi, guna mengapai apa yang diistilahkan dengan "cultural well-being". ${ }^{33}$ Dalam bahasa sederhana, motivationalcultural intelligence dimaknai sebagai: "Reflects the capability to direct attention and energy toward learning about and functioning in situations characterized by cultural differences," atau sesuatu yang merefleksikan kemampuan untuk memberikan perhatian dan energi terhadap pembelajaran tentang sesuatu atau memfungsikan dalam situasi dimana adanya perbedaan kultural. Pemaknaan sejatinya, yang memiliki kesamaan. Hanya lebih detail Ann C. Peng; Linn Van Dyne \& Kyoungjo Oh mengkategorikan motivasi menjadi: intrinsic motivation dan selfefficacy, keduanya didasarkan pada novel-cultures, dimana motivasi-intrinsik lebih tampak merefleksikan the sense atau kepekaan untuk berinteraksi dengan orang yang berbeda budaya, sehingga diartikan sebagai suatu kemewahan tersendiri. Sementara, self efficacy merefleksikan rasa percaya diri dan kemampuan secara langsung untuk memanage interaksi interkultural ketika memang situasi menuntutnya. ${ }^{34}$ Bagaimana dua hal ini diidentifikasi secara empiris?

Tesis yang dapat diajukan dari fakta empiris yang dikumpulkan, bahwa: "Siswa muslim dan non muslim pada Sekolah Menengah Atas di Kota Curup

${ }^{32}$ Ben R. Newell Arndt Bröder, "Cognitive Processes, Models and Metaphors in Decision Research," Judgment and Decision Making Vol. 3, no. 3 (2018): hlm. 106.

${ }^{33}$ Ann C. Peng Linn Van Dyne and Kyoungjo Oh, "The Influence of Motivational Cultural Intelligence on Cultural Effectiveness Based on Study Abroad: The Moderating Role of Participant's Cultural Identity," Journal of Management Education November (2014): hlm. 6.

${ }^{34}$ Linn Van Dyne and Kyoungjo Oh, hlm. 6. 
memiliki kepercayaan diri yang cukup tinggi untuk secara konsisten melakukan interaksi dan beradaptasi dengan perbedaan. Bahkan tidak hanya dianggap sebagai kemewahan, tapi diartikan sebagai keniscayaan dimana mereka tidak dapat menghindar dari perbedaan agama." Setidaknya ada beberapa informasi yang diberikan oleh informan terkait ini, dan kemudian diartikan sebagai fondasi argumentasi terhadap tesis yang diajukan di sini. Informan menerangkan bahwa:

"Saya sangat senang sekali jika Indonesia memiliki banyak perbedaan tetapi tetap bersama. Karena perbedaan kita dapat belajar banyak hal. Saya berharap tidak ada lagi perselisihan antar agama karena lebih baik berdamai dari pada berperang., 35

Informan lain mengutarakan:

Kita di Indonesia banyak agama pasti kita mengerti tentang agama yang lain, supaya kita mengerti bagaimana adatnya, sehingga kita tidak salah dalam berinteraksi. Setidaknya hal-hal yang boleh dan tidak boleh dalam agama masing-masing, dapat dipahami dengan baik." 36

Kedua informasi yang disampaikan oleh informan tersebut, menegaskan satu kata kunci, yakni: "Perbedaan merupakan previlage yang dimiliki oleh Indonesia. Dari perbedaan itu, masyarakat dapat belajar antara satu kearifan dengan kearifan lainnya. Sehingga terciptalah secara alamiah hubungan yang harmonis dalam perbedaan." Ini menegaskan bahwa motivasi intrinsik yang tumbuh dalam diri siswa muslim dan non muslim dapat diidentifikasi dari sikapnya yang menerima perbedaan dan memahami sebagai sebuah keniscayaan. Sehingga dapat beradaptasi dalam lingkungan yang multikultur, dapat mereka artikan sebagai sebuah keistimewaan. Sementara dalam dimensi self-efficacy, mayoritas informan mengakui bahwa beradaptasi, dan berinteraksi dengan teman yang berbeda agama; budaya; atau etnis merupakan sesuatu yang constructed-structuralistics. Artinya kemampuan itu tumbuh karena memang lingkungan sekolah yang mengkehendaki hal tersebut. Hal ini ditegaskan oleh informan, dimana menurutnya: "Kedamaian ada ketika kita mau menerima perbedaaan. Seperti dalam konsep bhineka tunggal ika 'walaupun berbeda-beda namun tetap satu jua". walaupun kita memiliki banyak perbedaan kita bisa

\footnotetext{
${ }^{35}$ Focus Group Discussion. Anukiron. Siswa SMA Xaverius. Tanggal 08/12/2018

${ }^{36}$ Focus Group Discussion. Intan. Siswa SMAN 01. Tanggal 21/12-2018.
} 
108 | Belajea: Jurnal Pendidikan Islam, Vol. 5, No. 01, 2020

menghargai apa yang ada dalam perbedaan itu dan menghargai perbedaan dan bisa menjadikan Indonesia menjadi lebih kuat." ${ }^{37}$ Informasi ini menguatkan, baik motivasi intrinsik maupun self-efficacy menjadi bagian yang hidup dalam keseharian siswa muslim dan non muslim pada Sekolah Menengah Atas di Kota Curup. Pertanyaan berikutnya, bagaimana hal ini juga berimplikasi pada kecerdasan berprilaku mereka?

Keempat, "Behaviour Cultural Intelligence"-sebagai sebuah kemampuan beradaptasi baik secara verbal maupun non verbal. Kemampuan ini tumbuh secara alamiah, dan proses yang konsisten untuk memahami perbedaan agama; budaya; dan etnis. Sehingga dengan kemampuan semacam ini akan lahir interaksi yang menyenangkan, dan mutual-understanding yang tinggi di antara anggota masyarakat. Meskipun secara identitas terdapat perbedaan yang kentara. Doreen J. Gooden; Carole Ann Creque \& Claudette Chin-Loy (2017) menguatkan hal tersebut dengan mengemukakan makna bahwa individu idealnya memiliki kemampuan verbal dan non-vernal dalam melakukan komunikasi dan berinteraksi dengan orang yang berbeda secara agama; budaya dan etnis. ${ }^{38}$ Dari penelusuran secara empiris, memang tidak terlalu kentara meningkatnya kemampuan verbal dan non verbal siswa muslim dan non-muslim pada Sekolah Menengah Atas di Kota Curup. Namun secara substantif, kemampuan verbal dan non verbal tidak hanya tercermin dari penguasaan terhadap bahasa etnis yang berbeda. Tapi juga kemampuan untuk memposisikan diri dalam perbedaan, sehingga cerdas dalam merespon perilaku dan tindakan individu lain yang barangkali berbeda dengan dirinya. Hal ini dapat tercermin dari konsistensi mengucapkan dan mengekpresikan empati; kepedulian; dan kesetiakawanan. Sehari-hari ini mewujud dalam bentuk 'inklusifitas' dalam mengucapkan selamat hari raya pada umat lain.

Demikian seorang informan mengutarakan sikap ketika dihadapkan pada masalah ujaran kebencian, dimana menurutnya: "Sering no comment karena semakin banyak komentar, malah menimbulkan berbagai perdebatan dan semakin menjadi, sehingga membiarkan saja dan tidak terlibat dalam perdebatan

${ }^{37}$ Focus Group Discussion. Ahmad Raradit. Siswa SMAN 01. Tanggal 21/12-2018.

${ }^{38}$ Doreen J. Gooden Carole Ann Creque and Claudette Chin-Loy, "The Impact Of Metacognitive, Cognitive And Motivational Cultural Intelligence On Behavioral Cultural Intelligence," International Business \& Economics Research Journal Vol. 16, no. 3 (2017): hlm. 224]. 
tersebut jauh lebih baik." 39 Informasi ini setidaknya menegaskan satu sikap dimana mampu menilai mana yang baik, dan berdampak positif bagi keharmonisan, ataupun sebaliknya. Ini termasuk apa yang diistilah dengan action atau behaviour cultural intelligence. Dengan demikian, secara keseluruhan pengalaman multikultural siswa muslim dan non muslim pada Sekolah Menengah Atas di Kota Curup, berimplikasi pada kecerdasan kultural. Sehingga kelak kehidupan umat beragama di Kota Curup akan jauh lebih baik. Karena generasi mudanya sudah pandai dan memahami hakikat perbedaan agama; budaya dan etnis dengan baik.

\section{Penutup}

Kecerdasan kultural siswa muslim dan non muslim pada Sekolah Menengah Atas di Kota Curup dapat ditelusuri dari tiga hal, yakni: metacognitive; cognitive; motivational dan behavioural. Adapun pada aspek metakognisi, siswa muslim dan non muslim pada Sekolah Menengah Atas di Kota Curup distimulus dalam focus group discussion, dengan memberikan kasus dan persoalan terkait multikulturalisme. Ketika mereka berhadapan dengan problematika multikultural ini, maka secara kualitatif, dapat dipahami bagaimana proses metakognisi mereka dalam mengindentifikasi persoalan yang ada. Dimensi yang diamati dan dipahami secara kualitatif meliputi bagaimana mereka menganalisis persoalan; dan melakukan demonstrasi terhadap persoalan tersebut. Ketika peserta focus group discussion, untuk kemudian disebut dengan informan, dari SMAN 01 dihadapkan dengan fakta berhubungan dengan permasalahan; diskursus terkait multikulturalisme.

Sementara itu, dalam hal kognisi sebagai sebuah proses dimana individu berusaha mendapatkan dan memahami informasi terkait berbagai hal. Dalam kajian ini, tentu terkait perbedaan identitas, bukan untuk mempersoalkan perbedaan tersebut. Tapi untuk memahami esensinya, agar menjadi kapital untuk beradaptasi dalam perbedaan tersebut. Hanya saja dalam strategi dan bagaimana mendapatkan informasi, ada berbagai style dan cara yang khas serta spesifik dilakukan oleh individu. Paige Lucas-Stannard telah mengurai hal tersebut. Menurutnya, setidaknya ada beberapa cara atau style dari proses kognitif, yakni: reflection-impulsivity; field dependent-independence, bolist-serialist dan deep-

\footnotetext{
${ }^{39}$ Focus Group Discussion. Anastasya. Siswa SMA Xaverius. Tanggal 08/12/2018
} 
110 | Belajea: Jurnal Pendidikan Islam, Vol. 5, No. 01, 2020

level/surface-level processing. Hal yang paling umum dari berbagai style tersebut adalah reflection-impulsivity, atau proses pengumpulan informasi dengan melihat detail dan berefleksi terhadap sumber informasi dan informasi itu sendiri. Pola ini yang kemudian juga ditemukan secara empiris pada siswa muslim dan non muslim pada Sekolah Menengah Atas di Kota Curup.

Dalam hal motivasi kecerdasan kultural sebagai kekuatan yang muncul dari diri individu untuk berinteraksi, guna mengapai apa yang diistilahkan dengan "cultural well-being", "Siswa muslim dan non muslim pada Sekolah Menengah Atas di Kota Curup memiliki kepercayaan diri yang cukup tinggi untuk secara konsisten melakukan interaksi dan beradaptasi dengan perbedaan. Bahkan tidak hanya dianggap sebagai kemewahan, tapi diartikan sebagai keniscayaan dimana mereka tidak dapat menghindar dari perbedaan agama." Terakhir, pada dimensi Behaviour Cultural Intelligence sebagai sebuah kemampuan beradaptasi baik secara verbal maupun non verbal. Kemampuan ini tumbuh secara alamiah, dan proses yang konsisten untuk memahami perbedaan agama; budaya; dan etnis. Sehingga dengan kemampuan semacam ini akan lahir interaksi yang menyenangkan, dan mutual-understanding yang tinggi di antara anggota masyarakat. Dari penelusuran secara empiris, memang tidak terlalu kentara meningkatnya kemampuan verbal dan non verbal siswa muslim dan non-muslim pada Sekolah Menengah Atas di Kota Curup. Namun secara substantif, kemampuan verbal dan non verbal tidak hanya tercermin dari penguasaan terhadap bahasa etnis yang berbeda. Tapi juga kemampuan untuk memposisikan diri dalam perbedaan, sehingga cerdas dalam merespon perilaku dan tindakan individu lain yang barangkali berbeda dengan dirinya. Hal ini dapat tercermin dari konsistensi mengucapkan dan mengekpresikan empati; kepedulian; dan kesetiakawanan. Sehari-hari ini mewujud dalam bentuk 'inklusifitas' dalam mengucapkan selamat hari raya pada umat lain.]

\section{Bibliografy:}

Aydin, Hassan, "Graduate Students Perceptions' on Multicultural Education: A Qualitative Case Study", Eurasian Journal of Educational Research, no. 57 (2014)

Aycan, Zeynep David C. Thomas, "Cultural Intelligence: A Theory-Based, Short Form Measure," Journal of International Business Studies, no. January (n.d.). 
A.Grant, Carl (ed.), Reasearch and Multicultural Education: From the Margins to the Mainstream (London: The Falmer Press, 2005).

C. Peng Linn, Ann, Van Dyne and Kyoungjo Oh, "The Influence of Motivational Cultural Intelligence on Cultural Effectiveness Based on Study Abroad: The Moderating Role of Participant's Cultural Identity," Journal of Management Education November (2014).

Cho, Sangmi Michaile E. Mor Barak, "Understanding of Diversity and Inclusion in a Perceived Homogeneous Culture: A Study of Organizational Commitment and Job Performance Among Korean Employees" (Administration in Social Work, 2008).

Dangmei, Jianguanglung, "Cultural Intelligence: Bridging the Cultural

Differences in the Emerging Markets," Indian Journal of Research Vol. 5, No. 9 (2016).

Horton, John, Liberalism, Multiculturalism and Tolerantion (New York: Palgrave McMillan, 1993).

J. Gooden, Doreen, Carole Ann Creque and Claudette Chin-Loy, “The Impact Of Metacognitive, Cognitive And Motivational Cultural Intelligence On Behavioral Cultural Intelligence," International Business \& Economics Research Journal Vol. 16, no. 3 (2017).

Parekh, Bikhu, Rethinking Multiculturalism: Cultural Diversity and 126 NO. 1. VOL. I. 2008 Political Theory (Cambridge: Harvard University Press, 2002).

Paige Lucas-Stannard, "Cognitive Styles: A Review of the Major Theories and Their Application to Information Seeking in Virtual Environments," Bibliographic Essay, March 13, 2019, hlm. 3, www.personal.kent.edu/ plucasst/Cognitive\%20Styles.pdf.

R. Newell, Ben, Arndt Bröder, "Cognitive Processes, Models and Metaphors in Decision Research," Judgment and Decision Making Vol. 3, no. 3 (2018). 
112 | Belajea: Jurnal Pendidikan Islam, Vol. 5, No. 01, 2020

Thomas, David C., Günter Stahl and Efrat Elron, "Cultural Intelligence: Domain and Assessment," International Journal of Cross Cultural Management Vol. 8, no. 2 (2008).

R. Sieck, Winston, Jennifer L. Smith and Louise J. Rasmussen, "Metacognitive Strategies for Making Sense of Cross-Cultural Encounters," Journal of Cross-Cultural Psychology Vol. 44, no. 6 (2013).

\section{Focus Group Discussion}

Focus Group Discussion, Wildan, Siswa SMAN 01. 21/12/2018

Focus Group Discussion, Nita Hairina, Siswa SMAN 01. 21/12/2018

Focus Group Discussion, Bonas Hasugian, Siswa SMAN 02. 23/12/2018

Focus Group Discussion, Anastasya, Siswa SMA Xaverius, 08/12/2018

Focus Group Discussion. Stanley Marco Effendi. Siswa SMAN 01. Tanggal 21/122018.

Focus Group Discussion. Hoksius Deariman Saragih. Siswa SMAN 02. Tanggal 21/12-2018.

Focus Group Discussion. Anastasya. Siswa SMA Xaverius. Tanggal 08/12-2018

Focus Group Discussion. Richard. Siswa SMAN 01. Tanggal 21/12-2018.

Focus Group Discussion. Desi. Siswa SMAN 01. Tanggal 21/12-2018.

Focus Group Discussion. Noconael Steven. Siswa SMAN 02. Tanggal 21/12/2018.

Focus Group Discussion.Natasya Intan. Siswa SMA Xaverius. Tanggal 08/12/2018

Focus Group Discussion. Anukiron. Siswa SMA Xaverius. Tanggal 08/12/2018

Focus Group Discussion. Ahmad Raradit. Siswa SMAN 01. Tanggal 21/12-2018.

Focus Group Discussion. Anastasya. Siswa SMA Xaverius. Tanggal 08/12/2018

\section{*Corresponding Authors}

Muhammad Sholihin can be contacted via email: sholihin@iaincurup.ac.id 